\title{
Consumer Health Column: Resources for New Parents - The First Year
}

\author{
Compiled by Heather Ganshorn
}

New parents often have many questions about their baby's health. Breastfeeding, starting solids, vaccinations, and growth and development are just a few of the topics that might come up in the first year of life. As the mom of a 2-year-old boy, I've experienced the information overload that comes with infancy and toddlerhood. Friends and family offer advice that is well intentioned but may be outdated or not based on medical evidence. The Internet, in addition to being a source of dubious information, is a gladiatorial arena for proponents of various parenting beliefs, with bloggers and commenters duking it out over everything from breastfeeding to whether or not to vaccinate your child.

As a medical librarian, I'm fortunate to know where to seek credible information on my child's health issues. Here is my roundup of evidence-based, parent-friendly resources to help Canadian parents navigate the first year of life. Due to space limitations, I have not covered infants with special needs or specific medical conditions, but some of the resources may contain relevant information for these parents.

\section{General infant health and development}

All parents should have an all-purpose baby health reference in the home, as many health questions may arise

The author with her 2-week-old son Malcolm, June 2010.

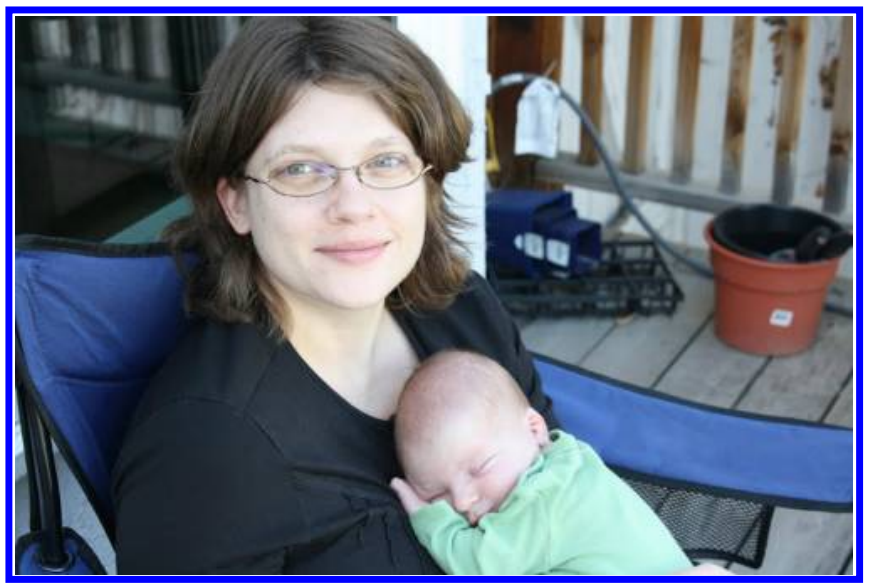

outside of doctors' office hours. Some regional health authorities produce their own guidebooks that combine current medical advice with links and phone numbers for local resources. These may be given to mothers in prenatal class or after delivery. If your health region produces these types of materials, you should collect them in your hospital library and keep copies on hand to give away to parents who haven't already received them.

\section{Books}

Sacks D, editor. The Canadian Paediatric Society guide to caring for your child from birth to age five. Mississauga, Ont.: J. Wiley \& Sons Canada; 2009.

This is the definitive health care guide for Canadian parents of infants and young children. In addition to the information on growth and development and common health issues, there is a section on the Canadian health care system that is useful for both newcomers and life-long Canadians. It's organized in a modular format that makes it easy to quickly find the information you need, and it offers clear guidance about whether to mention an issue at the child's next medical check-up, make an appointment to have the child seen, or immediately proceed to a clinic or emergency room.

Cook WJ, Johnson RV, Krych, EH, editors. The Mayo Clinic guide to your baby's first year. Rochester, MN: Mayo Foundation for Medical Education and Research; 2012.

As someone who found the Mayo Clinic Guide to a Healthy Pregnancy invaluable, I'm thrilled to see that they've come out with a high-quality guide to the first year of life. This book covers many of the same issues as the Canadian Paediatric Society (CPS) guide, but at 573 pages, it goes into greater depth and covers additional issues. There are sections on baby care, health and safety, growth and development, common illnesses and concerns, special needs, and a useful section on managing and enjoying parenthood. The writing is highly accessible, and evidence is laid out clearly, with risks and benefits of controversial practices such as circumcision and vaccination outlined in a nonjudgmental way. Colour photos enhance the text and provide useful visual diagnostic information on rashes and other conditions. 
Websites

Caring for Kids

http://www.caringforkids.cps.ca

This is the information portal of the CPS. It has a comprehensive section on pregnancy and babies. In addition to information on common illnesses and maintenance of good health, there is also great information here on topics like immunization, circumcision, and injury prevention. Visitors to the website can sign up for Front \& Centre, the monthly e-mail newsletter on child health issues from the CPS.

\section{KidsHealth Pregnancy and Baby Resources}

http://kidshealth.org/parent/pregnancy_newborn/

This web site is produced by the Nemours Foundation, an American nonprofit organization devoted to research and education on children's health. While this resource contains much of the same information found on Caring for Kids, you may find more in-depth information on certain topics.

\section{Post-partum mental health}

Many resources focus on the health of the child, but it's important for parents, and particularly mothers, to make time for self-care. Here are a couple of resources that promote maternal mental health.

\section{Book}

Roth Ledley, D. Becoming a calm mom: How to manage stress and enjoy the first year of motherhood. Washington, DC: American Psychological Association; 2008.

This book by a clinical psychologist and mother helps new moms to navigate the emotional ups and downs of the first year. The book offers moms a "toolbox" of cognitivebehavioural techniques for healthy thinking, behaviour, and communication with your child, along with relaxation techniques. There's a useful appendix on post-partum depression and anxiety and a supplementary web site at http://www.thecalmmom.com.

\section{Website}

Canadian Psychological Association Fact Sheet: PostPartum Depression

http://www.cpa.ca/psychologyfactsheets/postpartumdepres sion/

This brief, but informative, fact sheet outlines some of the myths and facts around post-partum depression along with a symptom chart, information on treatment, and links to a directory of Canadian health service providers in psychology.

\section{Infant mental health and brain development}

Most of the books and websites listed as "general resources" contain sections on brain and emotional development. However, the following website is an excellent resource that focuses specifically on infant mental health, brain development, and parenting practices to foster healthy mental development from infancy.

Zero to Three: National Center for Infants, Toddlers and Families

http://www.zerotothree.org

Zero to Three is an American nonprofit organization that conducts nonpartisan research and advocacy on the developmental needs of infants and toddlers. The organization's web site contains a wealth of information on child development for parents and caregivers. Sections on brain development, language development, infant and child learning, and psychology make this a wonderful complement to some of the other resources that focus more heavily on physical health. Check out the "Baby Brain Map" or download the "Little Kids, Big Questions" podcasts on early childhood development. Another wonderful and unique feature of the site is the section of resources for grandparents.

\section{Breastfeeding and starting solids}

According to a joint position statement from the CPS, Health Canada, and the Dietitians of Canada, "Healthy term infants should be exclusively breastfed to six months of age and then continue to be breastfed with appropriate complementary feeding to two years of age and beyond." Although breastfeeding is natural, it's not always easy. Here are a few top-notch sources for information and support.

\section{Books}

Newman J, Pitman T. Dr. Jack Newman's Guide to Breastfeeding, $1^{\text {st }}$ Rev. Ed. Toronto: Harper Collins; 2009 (new edition forthcoming in 2013).

Dr. Jack Newman is a Toronto paediatrician who founded Canada's first hospital-based breastfeeding clinic at the Hospital for Sick Children. He now runs his own private breastfeeding support clinic and is widely recognized as an expert in this area. His coauthor, Teresa Pitman, has over 30 years experience as a La Leche League Leader.

This book provides a very good overview of the evidence for breastfeeding, but more practically, it offers great tips on getting started and finding support, along with clearly outlined tips for addressing common issues and problems such as soreness, not enough milk, and jaundice. There are excellent sections on special situations such as premature babies and those with special needs, induced lactation for adoptive mothers, and breastfeeding while on medication. Another section deals with more of the emotional issues around breastfeeding including its impact on family relationships.

Newman's clinic web site at http://www.nbci.ca/ is an excellent resource, either as a supplement to the book or on its own. Under "Information and Videos," you'll find fact sheets and videos illustrating proper latch and various

\footnotetext{
${ }^{1}$ http://www.hc-sc.gc.ca/fn-an/consult/infant-nourrisson/recommen dations/index-eng.php
} 
positions for mother and baby. These fact sheets and videos are available in many languages, making it an invaluable resource for those serving clients from a variety of cultural backgrounds.

Wiessinger D, West D, Pitman T, La Leche League International. The womanly art of breastfeeding. 8th ed. New York: Ballantine Books; 2010.

Published by the La Leche League, this book offers much of the same content as Newman's book but with more of a "real-mom" spin. Despite the retro-sounding title, this guide tackles modern issues, like breastfeeding after a return to work, and provides links to online La Leche League resources.

Rapley G, Murkett T. Baby-led weaning: The essential guide to introducing solid foods and helping your baby grow up a happy and confident eater. New York: The Experiment; 2010.

Gill Rapley is an British public health nurse whose book challenges the dominant paradigm of starting babies out with purees. Instead, she advocates allowing babies to feed themselves solid foods according to their own preferences (with some qualifications and exceptions). Rapley conducted her master's thesis on the question of whether babies would spontaneously adopt solid foods from the beginning of weaning and found that they would. Since then, there have been several peer-reviewed publications around baby-led weaning (BLW) and a few websites by and for parents who practise it. There are many questions around BLW that have not yet been answered by the evidence (for example, differences in nutrient intake and risk of choking between BLW and conventional feeding). However, I am including this title because this seems to be the next big trend around introducing solid foods into babies' diets, and consumer health librarians may receive questions on the topic. Rapley appears to be the foremost expert in this area, and I found this book a useful resource when starting my son on solids.

\section{Websites}

\section{La Leche League International (http://www.llli.org) La Leche League Canada (http://www.lllc.ca).}

This international, consumer-led breastfeeding education organization promotes mother-to-mother breastfeeding support. The Canadian web site is a great place to locate a group or leader if you're seeking support, but unfortunately, it doesn't offer much in terms of general information. The international site offers a much greater range of resources, including answer pages (fact sheets), podcasts, and forums.

\section{Immunization}

No issue in child health is subject to greater misinformation than the vaccination debate. Search "vaccines" on the Internet or even on Amazon, and you'll discover that many people, some with M.D. or Ph.D. after their names, believe that vaccination is potentially or actually harmful to children, that it causes autism, that it compromises children's natural immune systems, that vaccines don't work, that diseases like smallpox and polio have vanished for other reasons, and that there's some sort of vaccination conspiracy involving doctors, the government, and pharmaceutical companies. The following books help parents to make evidence-based decisions about whether and to what extent to vaccinate their children.

\section{Books}

Gold R. Your child's best shot: A parent's guide to vaccination. 3rd ed. Ottawa: Canadian Paediatric Society; 2006.

This book is starting to look a bit dated, and may not include some newer vaccines, but most of the information is still current. Gold opens this book by discussing how vaccines work and how they are tested for safety and efficacy. The bulk of the book is divided into chapters on various vaccine-preventable diseases, in which the disease is described in great detail, from how the bacterium or virus operates biologically to symptoms, treatment, and impact of the disease on Canadians prior to the availability of a vaccine. Then the types of vaccines for the disease are described including how they are made and administered, vaccination schedules, possible side effects, reasons to avoid or delay that particular vaccine, and the vaccine's results including evidence of their effectiveness.

Offit PA, Moser CA. Vaccines and your child: Separating fact from fiction. New York: Columbia University Press; 2011.

Paul Offit is director of the Vaccine Education Center at the Children's Hospital of Philadelphia and author of a previous book, Autism's False Prophets, that attacks the "bad science" underlying many beliefs and untested therapies around autism spectrum disorders. This book devotes considerably more space than Gold's book in mythbusting such questions as whether vaccines cause allergies and asthma or whether they contain aborted fetal cells, antifreeze, or harmful preservatives. He then moves on to practical considerations such as dealing with children's fears of shots and vaccination of pregnant women, premature babies, and other special populations. The final sections provide information on individual vaccines and the reasons behind current vaccination schedules.

Though these books are excellent resources, vaccine science evolves every year. The best resource for current information on particular vaccines is always your regional health authority's documentation about the vaccines they use.

\author{
Heather Ganshorn, MLIS \\ Director, Science \& Engineering Libraries and \\ Cultural Resources \\ University of Calgary \\ E-mail: heather.ganshorn@ucalgary.ca
}

